\title{
Paciente inmunocompetente con criptococosis cerebral: reporte de un caso
}

\author{
Luis Cuitláhuac Becerra-Pedraza1, Daniel Arturo Martínez-Piña², Génesis Rocío Calles-Carmona \\ y Daniel San-Juan ${ }^{4}$ \\ ${ }^{1}$ Clínica de Enfermedad Cerebro Vascular; ${ }^{2}$ Departamento de Neurofisiología, Instituto Nacional de Neurología y Neurocirugía Manuel Velasco \\ Suárez, Ciudad de México; ${ }^{3}$ Departamento de Enseñanza, Hospital Psiquiátrico de Tampico, Tampico, Tamps.; ${ }^{4}$ Departamento de Investigación \\ Clínica, Instituto Nacional de Neurología y Neurocirugía Manuel Velasco Suárez, Ciudad de México. México
}

\begin{abstract}
Resumen
Mujer de 14 años que presentó cefalea holocraneana de inicio súbito y progresivo, acompañada de vómito sin respuesta a tratamiento médico. Ingresó a urgencias pediátricas con estado confusional, síndrome meningoencefálico, tomografía de cráneo normal y líquido cefalorraquídeo de aspecto transparente, hiperproteinorraquia, hipoglucorraquia, celularidad 15/mm, y tinta china y cultivo positivos para Criptococcus neoformans. Perfil viral, lúpico y de virus de la inmunodeficiencia humana negativos. Tratamiento con fluconazol $200 \mathrm{mg} / \mathrm{kg} /$ día, anfotericina B $0.7 \mathrm{mg} / \mathrm{kg} / \mathrm{dí}$ y y dexametasona $1 \mathrm{mg} / \mathrm{kg} / \mathrm{dí}$. A las 48 horas presentó edema cerebral sin respuesta al manejo médico, seguido de falla orgánica múltiple y muerte. Se ejemplifica la importancia de los pacientes inmunocompetentes de México en la infección por Cryptococcus spp.
\end{abstract}

PALABRAS CLAVE: Cefalea. Criptococosis cerebral. Cryptococcus gattii. Cryptococcus neoformans. Falla orgánica múltiple. Inmunocompetente. Síndrome meningoencefálico.

\begin{abstract}
A 14-year-old female, presenting sudden and progressive holocraneal headache along with incoercible vomiting arrived to emergency room. Acute confusional state and meningoencephalitis syndrome where identified. Brain computed tomography-scan with normal results was performed. Lumbar puncture with crystal-clear cerebrospinal fluid was obtained: low glucose, elevated proteins and cell-count of 15/mm. China-Ink and Criptococcus neoformans culture both positive. Viral, lupus-anticoagulant, and HIV tests negative. Fluconazole $200 \mathrm{mg} / \mathrm{kg} /$ day, amphotericin-B $0.7 \mathrm{mg} / \mathrm{kg} /$ day, dexamethasone $1 \mathrm{mg} / \mathrm{kg} /$ day were prescribed. 48-h later evolved to cerebral edema, multiple-organ-failure and death. Hereby we present a Cryptococcus spp. infection case report, addressing the public health challenge and vulnerability of immunocompromised patients in Mexico.
\end{abstract}

KEY WORDS: Headache. Cerebral cryptococcosis. Cryptococcus gattii. Cryptococcus neoformans. Multiple organ failure. Immunocompetent. Meningoencefalic syndrome.

\author{
Correspondencia: \\ Luis Cuitláhuac Becerra-Pedraza \\ Avda. Insurgentes Sur, 3877 \\ Col. La Fama, Del. Tlalpan \\ C.P. 14269, Ciudad de México, México \\ E-mail: Ic_bec@outlook.com
}

Fecha de recepción en versión modificada: 17-07-2016

Fecha de aceptación: 18-08-02016

DOI://dx.doi.org/10.24875/GMM.17002676
Gac Med Mex. 2017;153:911-914

Contents available at PubMed www.gacetamedicademexico.com 


\section{Introducción}

La criptococosis es una enfermedad micótica oportunista causada por un hongo levaduriforme y encapsulado de distribución mundial ${ }^{1}$. Existen dos variedades patógenas en el ser humano: Cryptococcus neoformans var. neoformans, causante de la mayoría de las infecciones en pacientes inmunocomprometidos, y var. gattii, que afecta a individuos inmunocompetentes y existe en ambas zonas tropicales y subtropicales ${ }^{2-4}$.

El diagnóstico de criptococosis está basado en una historia clínica detallada, ya que los síntomas dependen del área afectada en el sistema nervioso central (SNC). En caso de sospecha clínica después del análisis citológico, citoquímico y de tinción del líquido cefalorraquídeo (LCR), se debe realizar una prueba de ELISA (Enzyme-Linked ImmunoSorbent Assay) o una prueba de aglutinación de látex; cuando estas son negativas se debe esperar a los resultados del cultivo de LCR ${ }^{5}$. La meningitis por Cryptococcus spp. no tratada es fatal, mientras que el $60-70 \%$ de los pacientes sin sida tratados tienen buen pronóstico ${ }^{6,7}$.

El presente caso ejemplifica la importancia de la infección por Cryptococcus spp. en pacientes inmunocompetentes de nuestro país, pues a pesar del manejo médico y el tratamiento estandarizado la paciente tuvo disfunción orgánica y muerte.

\section{Presentación del caso}

Mujer de 14 años, habitante de una zona urbana en Morelia, Michoacán, con bajo nivel socioeconómico y malos hábitos higiénico-dietéticos. Cuenta con esquema de vacunación completo. Sin antecedentes personales, familiares ni psiquiátricos de relevancia. Inició su padecimiento en diciembre de 2014 con cefalea holocraneana de inicio súbito y progresivo, opresiva, constante, sin ritmo ni irradiación, 8/10 de intensidad en la escala verbal análoga de dolor (EVAD), tratada con paracetamol sin éxito, con un mes de evolución.

A su ingreso a urgencias en enero de 2014, la paciente se encontraba con cefalea holocraneana constante con intensidad 9/10 en la EVAD, acompañada de náuseas, vómito y crisis tónico-clónicas, con las siguientes constantes vitales: frecuencia cardiaca 110 latidos por minuto, frecuencia respiratoria 25 respiraciones por minuto, presión arterial 100/75 mmHg, deshidratación moderada, síndrome confusional agudo con estado de agitación psicomotriz y síndrome meningoencefálico. Las pruebas de laboratorio a su ingreso para biometría hemática con leucocitosis, química sanguínea y tiempos de coagulación son normales; tomografía de cráneo (TC) simple y contrastada normal (Fig. 1). Se inició tratamiento empírico con ceftriaxona, $1 \mathrm{~g}$ cada $12 \mathrm{~h}$ por vía intravenosa (i.v.), y vancomicina, $15 \mathrm{mg} / \mathrm{kg}$ cada $12 \mathrm{~h}$ i.v. Se realizó punción lumbar de LCR que mostró presión de apertura $80 \mathrm{mmH}_{2} \mathrm{O}$; citoquímico: color xantocrómico; aspecto transparente; proteínas $78 \mathrm{mg} / \mathrm{dl}$; glucosa $14 \mathrm{mg} / \mathrm{dl}$; celularidad $15 / \mathrm{mm}$; linfocitos $20 \%$; polimorfonucleares $76 \%$; y monocitos $4 \%$. En la tinta china se observó Cryptococcus neoformans (Fig. 2). Por tanto, se inició tratamiento a las $48 \mathrm{~h}$ con fluconazol $200 \mathrm{mg} / \mathrm{kg} / \mathrm{día}$, anfotericina B $0.7 \mathrm{mg} / \mathrm{kg} / \mathrm{día}$ y dexametasona $1 \mathrm{mg} / \mathrm{kg} /$ día. Los estudios de $\mathrm{TORCH}$, VDRL, parvovirus B19, virus de Epstein-Barr, anti-DNAdc 256Ul/ml, ANA 1:40 y VIH fueron negativos. El cultivo de LCR tuvo desarrollo de $C$. neoformans (sensible a flucitosina $\leq 1$ concentración mínima inhibitoria $[\mathrm{CMI}]$, anfotericina $\mathrm{B}=1 \mathrm{CMl}$, y fluconazol = $2 \mathrm{CMI})$.

A pesar del tratamiento, la paciente evolucionó con edema cerebral grave y deterioro neurológico (Fig. 3), desarrolló falla orgánica múltiple y 3 días posteriores falleció. No se realizó autopsia.

\section{Discusión}

La criptococosis cerebral en pacientes inmunocompetentes es poco frecuente, ya que solo se han reportado algunos casos en el mundo ${ }^{8}$. La variedad de Cryptococcus es un determinante para la infección en los pacientes inmunocompetentes, pero desafortunadamente en la mayoría de los casos se desconoce la variedad, ya que la realización de reacción en cadena de la polimerasa y ELISA no es una práctica habitual. Actualmente, la desnutrición crónica es un elemento importante en los países en vías de desarrollo"; no obstante, la convivencia con aves de corral y palomas es el factor de riesgo más frecuente. Los factores de riesgo identificados en nuestra paciente fueron habitar en una zona urbana marginal y la convivencia con aves de corral. En México, C. neoformans se ha aislado en el $20.7 \%$ de las muestras de excrementos de palomas colectados en áreas urbanas, y en menor proporción en verduras, frutas y excrementos de otras aves $^{10}$.

La presentación clínica más común es pulmonar, de donde puede diseminarse por vía hematógena al SNC y causar meningoencefalitis ${ }^{11-13}$. Al viajar por el 


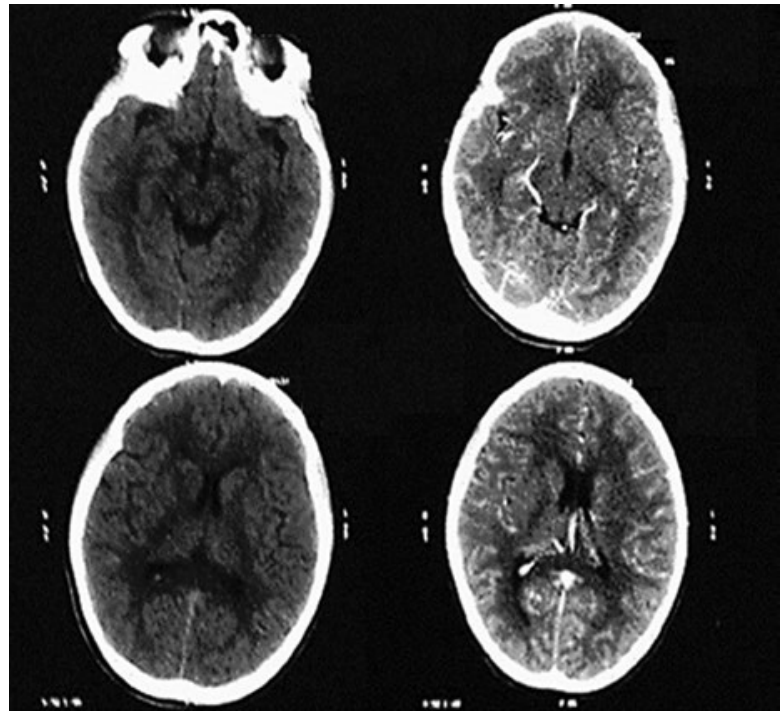

Figura 1. Tomografía de cráneo simple normal al ingreso en urgencias.

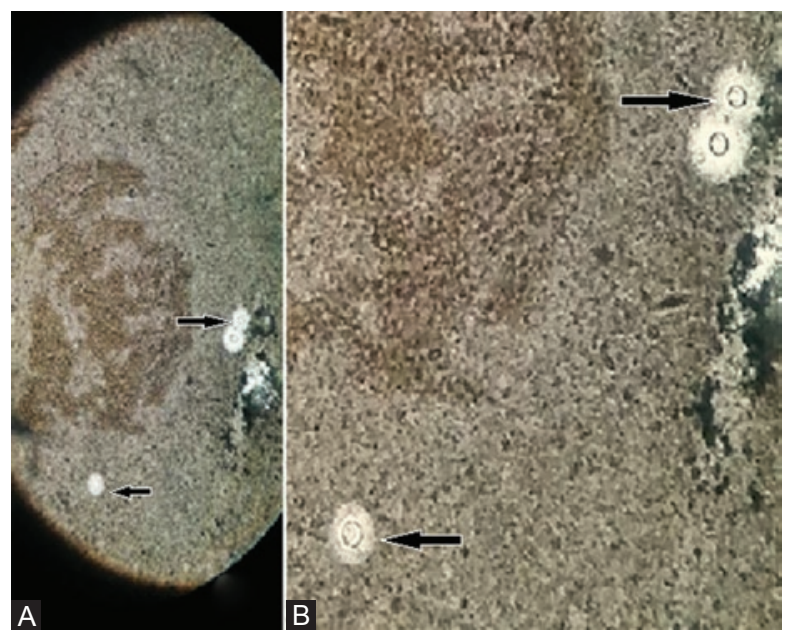

Figura 2. Bacterioscopico con tinta china donde se observan Cryptococcus neoformans (flechas). A: $10 \times$. B: $40 \times$.

torrente sanguíneo, el hongo inhibe la respuesta inmunitaria del huésped y la producción de factor de necrosis tumoral, entre otros ${ }^{14,15}$. Nuestra paciente no presentó datos de infección pulmonar previa; se han documentado casos de criptococosis pulmonar asintomáticos y de meningoencefalitis secundaria a infección pulmonar sin datos clínicos ni radiológicos pulmonares, y en estos casos la infección pulmonar es controlada por granulomas que desaparecen después de semanas 0 meses $^{16,17}$. La presentación de la criptococosis en el SNC puede ser como quistes en la corteza cerebral con reacción meníngea granulomatosa, o granulomas en la sustancia blanca llamados criptococomas $^{18,19}$, los cuales no se detectaron en

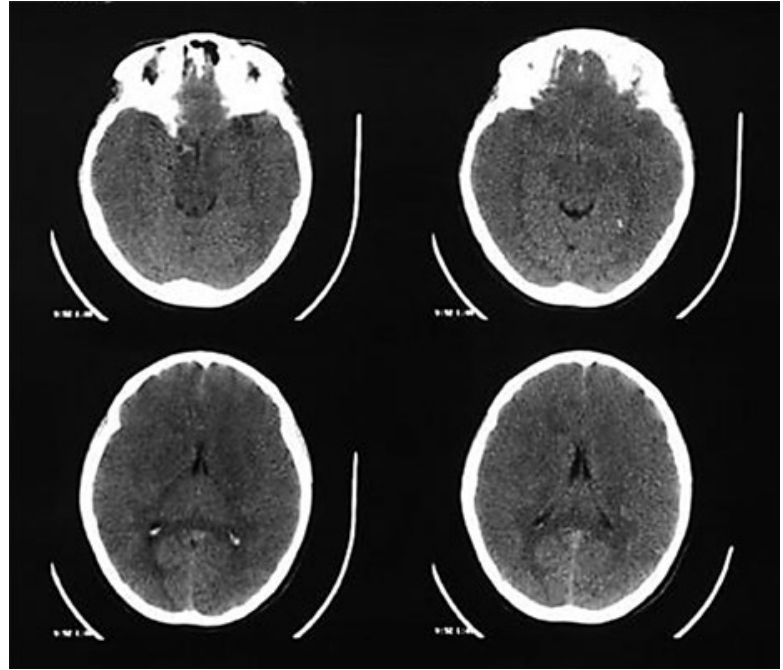

Figura 3. Tomografía de cráneo simple que muestra edema cerebral grave.

nuestra paciente; su condición médica impidió realizar una resonancia magnética.

Las manifestaciones clínicas de la criptococosis aparecen entre 1 y 2 semanas tras la exposición a esporas en heces de aves, plantas (eucaliptos) y animales (p. ej., koalas) ${ }^{20}$. Los pacientes inmunocompetentes pueden presentar la sintomatología después de meses o con una progresión lenta. La sintomatología es variada. Los síntomas iniciales son cefalea holocraneana progresiva, ataque al estado general y fiebre que solo se presenta en el $50 \%$ de los casos. En cuanto a la sintomatología neurológica, se han observado mayor prevalencia y más intensidad en pacientes inmunocompetentes, con manifestaciones locales o generales, según el área de afección por las levaduras $^{21-23}$. En nuestra paciente, la primera TC que se realizó fue normal; sin embargo, está documentado que la TC puede ser normal o mostrar criptococomas en un $38-58 \%$, edema cerebral, hidrocefalia o realce meníngeo. La resonancia magnética es más sensible para detectar nódulos dentro del parénquima cerebral; meninges, ganglios basales y mesencéfalo son anormales en el $40 \%$ de los pacientes que tienen presentación clínica típica de la infección ${ }^{23,24}$. El estudio citoquímico de LCR muestra pleocitosis linfocitaria, hiperproteinorraquia e hipoglucorraquia, y la prueba de tinta china es positiva en el $50 \%$ de los pacientes $\sin \operatorname{sida}^{25}$. El método más utilizado para el diagnóstico es el cultivo de Cryptococcus (sensibilidad del $90 \%$ ); no obstante, se ha reportado que la aglutinación con látex es la prueba diagnóstica con más altas sensibilidad y especificidad con títulos mayores de $1: 2048^{26}$. 
Independientemente del estado neurológico e inmunitario del paciente se recomienda el tratamiento de la criptococosis cerebral con anfotericina $B(0,7-1,0 \mathrm{mg} /$ $\mathrm{kg}$ por día i.v.) más flucitosina (100 mg/kg por día, por vía oral, en cuatro dosis divididas) durante al menos 4 semanas, y con complicaciones (hipertensión intracraneana, entre otras) se recomiendan 6 semanas de terapia de inducción para posteriormente iniciar la consolidación con fluconazol (400 mg al día) durante 8 semanas. Después de la inducción y la terapia de consolidación, se establece terapia de mantenimiento con fluconazol, $200 \mathrm{mg}$ por día durante 6-12 meses ${ }^{27}$.

El pronóstico es malo en los pacientes inmunodeprimidos e inmunocompetentes sin tratamiento; con tratamiento, la mortalidad reportada en todo el mundo en pacientes inmunocompetentes es del $27 \%$ y en los inmunodeprimidos es del $32 \%{ }^{28,29}$. La criptococosis cerebral en pacientes inmunocompetentes es poco frecuente; no obstante, puede tener un curso fatal a pesar del tratamiento antimicrobiano actualmente recomendado.

\section{Agradecimientos}

Agradecemos a la Fundación Armstrong por haber otorgado la beca de pregrado en el periodo de enero-junio de 2016 a Daniel Arturo Martínez Piña y Luis Cuitláhuac Becerra Pedraza en el Instituto Nacional de Neurología y Neurocirugía.

\section{Bibliografía}

1. Padilla MC, Navarrete $G$, Pérez $S$, et al. Criptococcosis diseminada asociada con VIH. Dermatol Rev Mex. 2012;56:126-31.

2. Tello M, Gutiérrez E, Béjar V, et al. Criptococosis. Rev Med Risaralda. 2013;19:147-53.

3. Azuero LF, Quintero P, Mayor L, et al. Meningitis en paciente VIH negativo. Rev Cienc Salud/Bogotá (Colombia). 2006;4:75-8.

4. García JL, Novoa AM. Criptococcosis. Una amenaza para pacientes inmunodeprimidos. Gaceta Médica Espirituana. 2011;13(3).

5. Gaona VA. Central nervous system and Cryptococcus neoformans. N Am J Med Sci. 2013;5:492-3.

6. Roebuck DJ, Fisher DA, Curie BJ. Cryptococosis in VIH negative patients: findings on chest radiography. Thorax. 1998;53:554-7.
7. Vázquez O, Martínez BI, Campos RT. Criptococosis. Historia natural y estado actual del tratamiento. Acta Pediatr Mex. 2005;26:18-28.

8. Lee SJ, Choi HK, Son J, et al. Cryptococcal meningitis in patients with or without human immunodeficiency virus: experience in a tertiary hospital. Yonsei Med J. 2011;52:482-7.

9. Mitchell TG, Perfect JR. Cryptococcosis in the era of AIDS - 100 years after the discovery of Cryptococcus neoformans. Clin Microbiol Rev. 1995;8:515-48.

10. Galnares JA, Loza S, Gómez F, et al. Criptococosis meníngea en un paciente inmunocompetente: reporte de un caso y revisión de la literatura. Revista Médica del Hospital General de México. 2014;77(3).

11. May RC, Stone NR, Wiesner DL, et al. Cryptococcus: from environmental saprophyte to global phatogen. Nature Reviews Microbiology. 2016;14:106-17.

12. Chang CC, Sorrell TC, Chen SC. Pulmonary cryptococcosis. Semin Respir Crit Care Med. 2015;36:681-91.

13. Gullo FP, Rossi SA, Sardi J, et al. Cryptococcosis: epidemiology, fungal resistance, and new alternatives for treatment. Eur J Clin Microbiol Infect Dis. 2013;32:1377-91.

14. Huston SM, Li SS, Stack D, et al. Cryptococcus gatti is killed by dendritic cells, but evades adaptive immunity by failing to induce dendritic cell maturation. J Immunol. 2013;191:249-61.

15. Price MS, Perfect JR. Host defenses against cryptococcosis. Immunol Invest. 2011;40:786-808.

16. Yang CJ, Hwang JJ, Wang TH, et al. Clinical and radiographic presentations of pulmonary cryptococcosis in immunocompetent patients. Scand J Infect Dis. 2006;38:788-93.

17. Ganiem AR, Indrati AR, Wisaksana R, et al. Asymptomatic cryptococcal antigenemia is associated with mortality among HIV-positive patients in Indonesia. J Int AIDS Soc. 2014;17:188-21.

18. Pyrgos V, Seitz A, Steiner C, et al. Epidemiology of Cryptococcal meningitis in the US: 1997-2009. Plos One. 2013;8:1-6.

19. Díaz JA, García JA, Mantilla JC, et al. Criptococoma en el sistema nervioso central de un paciente no inmunoafectado. Rev Neurol. 2008;46:97-101.

20. Agüero B, Garza D, Flores V, et al. Aislamiento y caracterización de Cryptococcus neoformans var. gattii a partir de muestras de Eucalyptus camaldulensis en la ciudad de México. Rev Iberoam Micol. 1999;16:40-2.

21. Lui G, Lee N, Ip M, et al. Cryptococcosis in apparently immunocompetent patients. QJM. 2006;99:143-51.

22. Galnares J, Loza S, Gómez F, et al. Criptococosis meníngea en un paciente inmunocompetente: reporte de un caso y revisión de la literatura. Rev Med Hosp Gen Mex. 2014;77:109-13.

23. Lui G, Lee N, Ip M, et al. Cryptococcosis in apparently immunocompetent patients. QJ Med. 2006;99:143-51.

24. Hoang L, Philips P, Galanis E. Cryptococcus gatti: a review of the epidemiology, clinical presentation, diagnosis, and management of this endemic yeast in the Pacific Northwest. Clin Microbiol Newsletter. 2011;33:187-95.

25. Loyse A, Moodley A, Rich P, et al. Neurological, visual, and MRI brain scan findings in 87 South African patients with HIV-associated cryptococcal meningoencephalitis. J Infect. 2015;70:668-75.

26. Gómez B, Zarco L. Criptococosis meníngea: características clínicas y de laboratorio. Acta Neurol Colomb. 2011;27:9-27.

27. Mukhopadhyay S. Role of histology in the diagnosis of infectious causes of granulomatous lung disease. Curr Opin Pulm Med. 2011;17:189-96.

28. Perfect J, Dismukes W, Dromer F, et al. Clinical practice guidelines for the management of cryptococcal disease: 2010 update by the Infectious Diseases Society of America. Clin Infect Dis. 2010;50:291-322.

29. Lizarazo J, Chaves O, Peña $Y$, et al. Comparacion de los hallazgos clínicos y de supervivencia entre pacientes VIH positivos y VIH negativos con criptococosis meníngea en un hospital de tercer nivel. Acta Médica Colombiana. 2012;37(2). 